\title{
Management of Psychological Effects through Counselling During HCV (Hepatitis) Treatment
}

\author{
Moni Chaudhary $^{1 *}$, Dr. Mridula Sharma ${ }^{2}$
}

\section{ABSTRACT}

Hepatitis (HCV) is a serious virus that can cause significant damage to the liver. Many individuals, who contact HCV, do so through blood transfusions or intravenous drug use. Additionally, the treatments available for HCV can cause negative side effects and decrease a client's quality of life. Psychiatric disorders or drug addiction are often regarding as contraindications against the use of interferon (IFN- $\alpha$ ), ribavirin and sofosovior in patients with chronic hepatitis C. Our aim was to find out role of counseling on mental side effect of treatment with IFN- $\alpha$, ribavirin and sofobuvior in different psychological risk groups. Individuals with HCV also experience psychological problems as a result. For instance, many people who are diagnosed with HCV are of low socioeconomic status and have limited access to adequate health care. Other psychological conditions that are common among individuals with HCV include discrimination, depression, and substance misuse. We suggested that Psychologists may be able to not only help with co morbid conditions but also help clients deal with the adverse side effects of medication and the psychological stigma and discrimination surrounding HCV.

Keywords: Management, Counselling, HCV (Hepatitis) Treatment

Worldwide, 150 million people are estimated to be chronically infected with hepatitis C virus (HCV) (WHO Hepatitis C Fact Sheet). The hepatitis C virus is the member of the flaviviridae family of ribonucleic acid (RNA) viruses. Hepatitis $\mathrm{C}$ virus is the cause of hepatitis c and some cancer lymphomas in humans (Ferri, Clodoveo. 2015). The virus reproduces by making many copies of itself in liver cells. The hepatitis $C$ virus in the liver can cause liver inflammation and cell death. (Farrell, G.C. 2002). The illness can have detrimental physical health consequences and can lead to liver cancer or cirrhosis of the liver. There are six main genotype (Strains) of hepatitis C. Each genotype contain numerous subtypes, labeled a, b, or c. Genotypes 1a and 1b (54\% prevalence) and 3a (37\% prevalence) are the most common genotype. Hepatitis C was

\footnotetext{
${ }^{1}$ Research Scholar, Department of Psychology (Meerut College, Meerut). Chaudhary Charan Singh University, Meerut

${ }^{2}$ Assistant Professor, Department of Psychology (Meerut College, Meerut). Chaudhary Charan Singh University, Meerut

*Responding Author

(C) 2016 I M chaudhary, M Sharma; licensee IJIP. This is an Open Access Research distributed under the terms of the Creative Commons Attribution License (http://creativecommons.org/licenses/by/2.0), which permits unrestricted use, distribution, and reproduction in any Medium, provided the original work is properly cited.
} 
discovered by scientists in 1988 and found to be responsible for most of case of 'non-A, non- B hepatitis'. Early studies has confirmed that hepatitis $\mathrm{C}$ spread through blood to blood contact. An accurate test to diagnoses hepatitis $\mathrm{C}$ becomes available in Australia, in 1990. The test detected antibodies produced in reaction to the hepatitis $\mathrm{C}$ virus. The remaining people with hepatitis $\mathrm{C}$ were infected in other ways, including:

- Unsterile tattooing or body piercing procedures.

- Unsterile medical procedure or vaccinations (particularly in countries with high rate of hepatitis C).

- Needle - stick injuries and accidental exposure to infected blood or blood products.

- Exposure to blood in the home.

- Some other form of blood to blood contacts.

- Some people with hepatitis C cannot identify, how they were infected.

Research shows that the risk of transmission to a baby during pregnancy or childbirth is low. The risk is about $6 \%$ if you have detectable levels of the virus in your blood, that is, if you have a PCR test shows the presence of virus in your blood .(Dore GJ, Kaldor JM, McCaughan W. 1997).

Other factors which affect the progression of liver disease include:

- Age when first infected (people infected over the age of 40 years, experience faster disease progression).

- Male gender

- Alcohol use

- Co- infection with hepatitis B virus and/or HIV

- Obesity (Poynard, T., et. al., 2001).

Mental illness and hepatitis frequently co-occur (Rosenberg et al., 2001; Rosenberg et al., 2003). People who have mental illness are at greater risk than the general public for exposure to infectious diseases, including chronic hepatitis ( Rosenberg et al., 2001).

For instance, in a study of veterans with hepatitis C, ( Fireman, Indest, Blackwell, Whitehead, and Hauser, 2005) found that 93 percent of subjects had one or more psychiatric or substance use disorders at the time of or before the study.

Behavioral health conditions are not absolute contraindications for chronic hepatitis treatment. As healthcare providers increasingly consider treating hepatitis in patients with mental disorders, they might turn to behavioral health providers to assess their patients for readiness for antiviral treatment. In addition, behavioral health treatment providers might have clients who have chronic hepatitis and who require support through the lengthy and challenging hepatitis treatment process. 


\section{THE NEED FOR COUNSELING}

Counselors are in a unique position to provide education, emotional support, and other types of assistance for clients who have hepatitis and substance use disorders (SUDs). However, most treatment programs do not have components in place to address viral hepatitis. According to the 2007 National Survey of Substance Abuse Treatment Services, only 22 percent of treatment facilities offer onsite screening tests for hepatitis B; 23 percent offer onsite screening for hepatitis C (Office of Applied Studies, 2007). Other studies have shown that only 54 percent of treatment programs provide education about hepatitis, and many counselors are uninformed or misinformed about the disease (Astone, Strauss, Vassilev, \& Des Jarlais, 2003).

Depending on the resources available, counselors might be able to implement only some of the strategies presented for supporting clients, who have hepatitis. Readers are encouraged to accomplish what they can to improve SUD treatment practices for their clients and to advocate for client access to services that cannot be implemented immediately.

\section{OBJECTIVE}

- To Manage Psychological Effects Through Counselling During HCV (Hepatitis C) Treatment.

\section{METHODLOGY}

During, One year practice at a tertiary care hospital, meet with 110 patients, infected with HCV, only those patients were selected to observing there problems (Psychological), Who had taken therapy to cure HCV under the treatment of Gastroenterologist.

The nature of treatment is long as three months, so we can talk, interact, and counseled patients every week for three months. An unstructured interview was also conducted to know their problems.

\section{Procedure to Collect Information:}

In the beginning of treatment, we took only general information, like; name, age, sex, lived, contact details, marital status, and number of children's etc. and also knowing about source of $\mathrm{HCV}$ virus. Between these kind of collecting information, also conducted an unstructured interview and discussed their though issues related HCV, which creates barrier to live their life easily. We also discuss about their physical health and psychological problems. These problems also may be results of side effects of treatment, there is lots of side effect during the treatment and all depends person to person. 
These are:

\begin{tabular}{|l|l|}
\hline Infections and Infestation & Viral infection, Bacterial infection, and Bronchitis. \\
\hline Blood Disorder & Anemia and Neutropenia. \\
\hline Psychiatric Disorder & $\begin{array}{l}\text { Depression, anxiety, emotional lability, Concentration, insomnia, } \\
\text { and Aggression. }\end{array}$ \\
\hline Nervous System Disorder & Headache, Dizziness and Amnesia. \\
\hline Vascular Disorder & Hypertension and Flushing \\
\hline Gastrointestinal Disorder & Vomiting, Nausea, Diarrhea, and Abdominal Pain \\
\hline General Disorder & Fatigue, Chest Pain, Pain and Influenza like illness. \\
\hline
\end{tabular}

\section{RESULTS \& DISCUSSION}

Treatment of chronic hepatitis is challenging for most people. Behavioral health treatment providers might have clients who need assistance with making psychological adjustments to having a chronic disease (e.g., coping with a chronic disease, learning about hepatitis, making healthful lifestyle changes) and making decisions related to having hepatitis (e.g., whether/how to disclose the condition to others, deciding on whether to undertake antiviral therapy, adhering to the treatment regimen).

In this treatment we use these tips:

- Using effective counseling strategies, including motivational approaches

- Providing reliable information about hepatitis

- Building the therapeutic relationship

- Helping clients understand their diagnoses

- Incorporating client needs in substance abuse treatment planning

- Developing a plan to prevent infecting others and to prevent further liver damage

- Using motivational approaches

- Confronting the social ramifications of disclosing hepatitis status

- Addressing relapse

- Building support system

Behavioral health treatment providers can help clients, who are currently ineligible for hepatitis treatment become eligible. For example, they can motivate clients to attend medical appointments. Helping a client become ready for treatment can take several months (Scheft \& Fontenette, 2005). Behavioral health treatment providers can work with a client's healthcare provider and advocate a referral for hepatitis treatment when clients are ready.

\section{Diet}

Healthy diet (low-fat, high-fiber) and exercise to prevent/treat obesity/fatty liver. Extra protein and fluids while on IFN therapy.

\section{Patient Education}

Educate patients to avoid alcohol, tobacco, and drugs (including marijuana) at diagnosis; refer to rehab/12-step program and monitor for relapse. Caution patients against internet/alternative medicine claims of false cures. Recommended avoidance of herbs (may contain hepatotoxins and 
contaminants) as well as hepatotoxins medication and vitamins/supplements (Anne $\mathrm{M}$ et al., 2012).

\section{The Counsellor role}

Medical care providers that once would have denied hepatitis treatment to people with substance use disorders (SUDs) now routinely screen and evaluate such people and often recommend antiviral treatment. Pharmacotherapy for an opioid addiction, for example, is no longer considered a contraindication to evaluation, care, or treatment of chronic hepatitis (Kresina et al., 2008). Informed counselors can help their clients make decisions about medical care for hepatitis and can support the clients in managing the risks and benefits that come with any decision

Using motivational approaches, the counsellor can help clients understand the relationship between good health and recovery (Litwin et al., 2005). Counsellors can identify the strengths, clients have demonstrated in counseling sessions and encourage clients to develop ways to use those strengths to cope with current health challenges and provides sources of information about motivational interviewing and counselling.

\section{Peer Counselling and Support}

In a study at a residential treatment program (Munoz-Plaza et al., 2004), clients most frequently recommended the use of peer counsellors as a way to enhance hepatitis treatment services. These clients found that peers, who had experience with HCV infection, were more valuable than "even the most knowledgeable and well-trained staff person” (Munoz-Plaza et al., 2004). Peers can facilitate or co-facilitate support groups; act as mentors to newly diagnosed clients; and provide information, support, and assistance (e.g., provide transportation, accompany clients to medical appointments). Peers can be clients who are farther along in hepatitis treatment, graduated clients, or volunteers from the community.

\section{Family Support}

Families might be supportive or might react badly to a family member's diagnosis of hepatitis. Clients might need the counselor's help in telling family members about a hepatitis diagnosis. Families might not be willing or able to support the client (e.g., family members might be using drugs). However, counsellors can reduce families' fears and encourage families through the following:

- Educate family members about hepatitis. Families need the same information as clients about the illness, its treatment, the potential effects on a client's SUD recovery, and the increased risk of relapse to substance use.

- Help families adjust to lifestyle changes. Some clients might make lifestyle changes, particularly in diet and sexual behavior, following a diagnosis of hepatitis or as part of their substance abuse treatment (Castera, Constant, Bernard, de Ledinghen, \& Couzigou, 2006; Fabris et al., 2006). These changes affect family members. 
Psychologists are also trained in social and behavioral sciences, and although they are not the first line of defense in the treatment of HCV, they are a vital component in the overall treatment regimen. Donna M. Evon of the Division of Gastroenterology and Hepatology at the University Of North Carolina School Of Medicine recently published a paper emphasizing the importance of psychological treatment for those living with HCV. Evon says that many individuals with HCV do not adhere to their medical treatment regiments because of other psychological issues such as substance abuse. Working with a psychologist as well as a medical doctor can help these individuals address their addiction issues, which could then increase their commitment to $\mathrm{HCV}$ treatment.

Evon believes that psychologists need to be proactive in their involvement. She suggests that mental health clinicians ally themselves with hepatologists and gastroenterologists in order to increase the overall level of care for these clients.

\section{CONCLUSION}

Patients with HCV infection had complex psychiatric and psychosocial problems. These problems are challenges for management of $\mathrm{HCV}$ infection, affect the patient's care significantly, and might alter the course of the disease. A multidisciplinary approach, a supportive environment, and a nonjudgmental healthcare team are required for optimal medical and psychosocial management of patients with HCV. Evon adds, "Biomedical advances in HCV and antiviral treatment have created a fertile field in which psychologists are uniquely positioned to make important contributions to HCV management and treatment.”

\section{REFERENCES}

Anne M Walsh, Frank J Domino (2012). The 5-Minute Clinical Consult $20^{\mathrm{IH}}$ Edition. Wolters Kluwer Health/Lippincott Williams \& Wilkins, Vol: 1, A-J.

Astone JM, Strauss SM, Vassilev ZP, Des Jarlais DC (2003). Provision of hepatitis C education in a nationwide sample of drug treatment programs. Drug Education.33(1):107-117.

Castera L, Constant A, Bernard PH, de Ledinghen V, Couzigou P (2006). Lifestyle changes and beliefs regarding disease severity in patients with chronic hepatitis C. Journal of Viral Hepatitis. 13:482-488.

Dore GJ, Kaldor JM, Mc Caughan GW (1997). Systematic review of role of polymerase chain reaction in defining infectiousness among people infected with hepatitis $\mathrm{C}$ virus.BMJ: Aug 9;315 (7104):333-7.

Evon D M, Golin CE, Fried MW, Keefe FJ (2012). Chronic hepatitis C and antiviral treatment regimens: Where can psychology contribute? Journal of Consulting and Clinical Psychology. Advance online publication. doi: 10.1037/a0029030.

Fabris P, Tositti G, Giordani MT, Baldo V, Pignattari E, Cantons S, et al.(2006). Assessing patients' understanding of hepatitis $C$ virus infection and its impact on their lifestyle. Alimentary Pharmacology and Therapeutics.23(8):1161-1170. 


\section{Management of Psychological Effects through Counselling During HCV (Hepatitis) Treatment}

Farrell GC (2002).Hepatitis C, other liver disorder,and liver health: A practical guide. Sydney, Australiya: MacLennan and Petty Pty Limited.

Ferri, Clodoveo (2015). "HCV syndrome: A constellation of organ- and non-organ specific autoimmune disorders, B-cell non-Hodgkin’s lymphoma, and cancer". World Journal of Hepatology 7 (3): 327.doi:10.4254/wjh.v7.i3.327. ISSN 1948-5182

Fireman M, Indest DW, Blackwell A, Whitehead AJ, Hauser P (2005). Addressing tri-morbidity (hepatitis C, psychiatric disorders, and substance use): The importance of routine mental health screening as a component of a co management model of care. Clinical Infectious Diseases. 40 (Suppl 5):S286-S291.

Kresina TF, Sylvestre D, Seeff L, Litwin AB, Hoffman K, Lubran R, et al. (2008). Hepatitis infection in the treatment of opioid dependence and abuse. Substance Abuse: Research and Treatment.1:15-61.

Litwin AH, Soloway I, Gourevitch MN (2005). Integrating services for injection drug users infected with hepatitis $C$ virus with methadone maintenance treatment: Challenges and opportunities. Clinical Infectious Diseases. 40 (Suppl 5):S339-S345.

McCaw, R.,Moaven, L.D., Locarnini, S.A. \& Bowden, D.S. (1997). Hepatitis C virus genotype in Australia. Journal of viral Hepatitis, 4, 351-357.

Munoz-Plaza CE, Strauss SM, Astone JM, Des Jarlais DC, Hagan H. (2004). Drug treatment programs as sites of opportunity for the delivery of hepatitis $\mathrm{C}$ prevention education: Client and staff perspectives. Journal of Drug Issues. 34(4):861-878.

Office of Applied Studies. National Survey of Substance Abuse Treatment Services: (2007), Data on substance abuse treatment facilities. Rockville, MD: Substance Abuse and Mental Health Services Administration; 2007. (DASIS Series: S-44 HHS). Publication No (SMA) 08-4348

Poynard, T., Ratziu, V., Charlotte,F., Goodman, Z., Mc Hutchison, J.G. \& Albrecht, J.(2001). Rates and risk fectors of liver fibrosis progression in patients with chronic hepatitis c. Journal of hepatology,34(5),730-739.

Rosenberg SD, Goodman LA, Oshe FC, Swartz MS, Essock SM, Butterfield MI, et al. (2001). Prevalence of HIV, hepatitis B, and hepatitis C in people with severe mental illness. American Journal of Public Health. 91(1):31-37.

Rosenberg SD, Swanson JW, Wolford GL, Osher FC, Swartz MS, Essock SM, et al. (2003). The five-site health and risk study of blood-borne infections among persons with severe mental illness. Psychiatric Services. 54(6):827-835.

Scheft H, Fontenette DC. (2005). Psychiatric barriers to readiness for treatment for hepatitis C virus (HCV) infection among injection drug users: Clinical experience of an addiction psychiatrist in the HIV-HCV co infection clinic of a public health hospital. Clinical Infectious Diseases. 40 (Suppl 5):S292-S296.

The World Health Organization (WHO) (2014). Hepatitis C Fact Sheet. Available. From:http://www.who.int/mediacentre/factsheets/fs164/en/index.html.Accessed 15 July 2014. 